\title{
Enzymic colorimetry-based DNA chip: a rapid and accurate assay for detecting mutations for clarithromycin resistance in the 23S rRNA gene of Helicobacter pylori
}

\author{
Correspondence \\ Feng-Xiang Jing \\ jingfengx@163.com \\ Hui-Min Wang \\ zj6669@163.com
}

Received 4 March 2009

Accepted 16 July 2009

\author{
Shi-Hai Xuan, ${ }^{1}$ Yu-Gui Zhou, ${ }^{1}$ Bo Shao, ${ }^{1}$ Ya-Lin Cui, ${ }^{1}$ Jian Li, ${ }^{1}$ \\ Hong-Bo Yin, ${ }^{1}$ Xiao-Ping Song, ${ }^{1}$ Hui Cong, ${ }^{2}$ Feng-Xiang Jing, ${ }^{3}$ \\ Qing-Hui Jin, ${ }^{3}$ Hui-Min Wang ${ }^{2}$ and Jie Zhou ${ }^{1}$
}

${ }^{1}$ Department of Clinical Laboratory, The People's Hospital of Dongtai City, Dongtai 224200, PR China
${ }^{2}$ Center of Laboratory Medicine, Affiliated Hospital of Nantong University, Nantong 226001,
PR China
${ }^{3}$ Biochip Laboratory, Shanghai Institute of Microsystem and Information Technology, Chinese
Academy of Sciences, Shanghai 200050, PR China

Macrolide drugs, such as clarithromycin (CAM), are a key component of many combination therapies used to eradicate Helicobacter pylori. However, resistance to CAM is increasing in $H$. pylori and is becoming a serious problem in $H$. pylori eradication therapy. CAM resistance in $H$. pylori is mostly due to point mutations (A2142G/C, A2143G) in the peptidyltransferase-encoding region of the 23S rRNA gene. In this study an enzymic colorimetry-based DNA chip was developed to analyse single-nucleotide polymorphisms of the 23S rRNA gene to determine the prevalence of mutations in CAM-related resistance in $H$. pylori-positive patients. The results of the colorimetric DNA chip were confirmed by direct DNA sequencing. In 63 samples, the incidence of the A2143G mutation was $17.46 \%$ (11/63). The results of the colorimetric DNA chip were concordant with DNA sequencing in $96.83 \%$ of results (61/63). The colorimetric DNA chip could detect wild-type and mutant signals at every site, even at a DNA concentration of $1.53 \times 10^{2}$ copies $\mu^{-1}$. Thus, the colorimetric DNA chip is a reliable assay for rapid and accurate detection of mutations in the 235 rRNA gene of $H$. pylori that lead to CAM-related resistance, directly from gastric tissues.

\section{INTRODUCTION}

Helicobacter pylori is a Gram-negative bacterium involved in digestive diseases such as peptic ulcers, gastritis and mucosaassociated lymphoid tissue, and is a risk factor in the development of gastric cancer (Dunn et al., 1997). Eradication of $H$. pylori infection can cure peptic ulcer disease and reduce the risk of gastric adenocarcinoma and mucosa-associated lymphoid tissue (Sung et al., 1995). Indeed, macrolide drugs such as clarithromycin (CAM) form a key component of most treatment recommendations in eradicating H. pylori (Treiber et al., 2005). In recent years, however, the increasing use of CAM has resulted in the development of resistance. It is now widely accepted that resistance to CAM is the main reason for failure in $H$. pylori eradication therapy (Sezgin et al., 2008; Treiber et al., 2005).

Many laboratories use agar disc diffusion or an Etest for the determination of macrolide resistance after isolation of the

Abbreviations: CAM, clarithromycin; NC, negative control; PC, positive control; SNP, single-nucleotide polymorphism. pathogen from gastric biopsies. Both methods require further serial subcultivation for several days and neither identifies the type of point mutation present in the strain (Rüssmann et al., 2001). Recently, numerous molecular techniques have been developed to detect point mutations in the 23S rRNA gene such as fluorescent in situ hybridization, PCR-RFLP, DNA sequencing and an oligonucleotide line probe assay (Kim et al., 2002; Rüssmann et al., 2001; Sezgin et al., 2008; Van Doorn et al., 2001). However, these are also time-consuming and laborious methods. Here, we have established an enzymic colorimetry-based DNA chip for the detection of point mutations in the 23S rRNA gene of $H$. pylori that are associated with resistance to CAM. We also evaluated the sensitivity and specificity of this method by comparison with DNA sequencing.

\section{METHODS}

Sample collection and DNA extraction. Gastric tissues were obtained from 63 patients during gastric endoscopy at the Affiliated 
Hospital of Nantong University and The People's Hospital of Dongtai City, PR China, from October 2007 to January 2008. All patients were enrolled randomly. Primary and secondary drug resistance were not classified. The mean age of the patients was 48.7 years (range 19-62 years). They had erosive gastritis (17 patients, $26.98 \%$ ), gastroduodenal ulcers (38 patients, $60.32 \%$ ), atrophic gastritis (5 patients, $7.94 \%$ ) or gastric cancer (3 patients, $4.76 \%$ ). One piece of biopsy specimen was obtained from the patient for the purpose of genomic DNA extraction, whilst another was obtained from the same patient for cultivation. All patients were infected with $H$. pylori, confirmed by a rapid urease test (Livzon Group Reagent Factory) and by a $\left[{ }^{14} \mathrm{C}\right]$ urea breath test (GMS Pharmaceutical). DNA was extracted from each bacterial and biopsy specimen with a DNA extraction kit (TaKaRa) according to the manufacturer's protocol. The isolated DNA was stored at $-20{ }^{\circ} \mathrm{C}$.

Culture conditions and antibiotic susceptibility test. Biopsy specimens were cultured on Columbia agar with $10 \%$ sheep blood and Dent antibiotic supplement (Oxoid) at $37{ }^{\circ} \mathrm{C}$ for $3-5$ days under microaerobic conditions $\left(5 \% \mathrm{O}_{2}, 10 \% \mathrm{CO}_{2}, 85 \% \mathrm{~N}_{2}\right)$. Identification of $H$. pylori was based on colony morphology, microscopy, and positive urease, catalase and oxidase activities. The MICs of $H$. pylori to CAM were evaluated with Etest strips (AB Biodisk). Strains were classified as resistant to CAM when the MIC was $>1 \mu \mathrm{g} \mathrm{ml}^{-1}$.

Amplification of the 23S rRNA gene of $\boldsymbol{H}$. pylori by PCR. Primers used for PCR amplification (GenBank accession no. U27270) were an H. pylori forward primer (HPFP: 5'-ATGAATGGCGTAACGAGATGGGAGC-3', nt 2050-2074) and reverse primer (HPRP: 5' CCAGTCAAACTACCCACCAAGCATT-3', nt 2335-2311). The amplification product was $285 \mathrm{bp}$. The HPRP primer was $5^{\prime}$ labelled with digoxigenin. PCR amplification was in a $50 \mu \mathrm{l}$ volume containing $50 \mathrm{ng}$ genomic DNA, $1 \times$ PCR buffer, $1.5 \mathrm{mmol} \mathrm{MgCl}_{2}, 0.2 \mu \mathrm{mol}$ each primer, $1.0 \mathrm{U}$ Taq polymerase and $200 \mu \mathrm{mol}$ each dNTP. Amplification was carried out in a DNA thermal cycler (PTC-200; Bio-Rad). Cycling parameters were $5 \mathrm{~min}$ of denaturation at $94{ }^{\circ} \mathrm{C}$; 30 cycles of $30 \mathrm{~s}$ at $94{ }^{\circ} \mathrm{C}, 30 \mathrm{~s}$ at $53{ }^{\circ} \mathrm{C}$ and $30 \mathrm{~s}$ at $72{ }^{\circ} \mathrm{C}$; and a final elongation step at $72{ }^{\circ} \mathrm{C}$ for $10 \mathrm{~min}$. Amplification products were routinely analysed by electrophoresis in $2.0 \%$ agarose gels, which were stained with ethidium bromide, and then stored at $4{ }^{\circ} \mathrm{C}$.

Design of probes. A total of 13 oligonucleotide probes were designed using Primer 5.0 software from the conservative regions of the 23S rRNA gene of $H$. pylori according to GenBank accession no. U27270. The sequences of the probes were analysed with a BLAST search. The probe lengths were between 15 and $18 \mathrm{nt}$, and the $5^{\prime}$ end of each probe was modified by adding poly(T) and was aminomodified for immobilization. The positive-control (PC) probe was designed to be complementary to HPRP to evaluate the quality of the oligonucleotide chip fabrication and hybridization. The negativecontrol (NC) probe used had two base mismatches compared with the sequence of the PC probe. The probes sequences are shown in Table 1.

Mutant construction by site-directed mutagenesis. To verify the specificity of the probe, five mutant clones were constructed by sitedirected mutagenesis with a QuikChange site-directed mutagenesis kit (Stratagene) according to the manufacturer's protocol. The mutants were cloned in vector pGEM-T (Promega) and the clones were analysed to confirm the mutagenic sequences. The concentrations of recombinant plasmids were detected using a nucleic acid and protein analyser (U-0080D; Hitachi). Recombinant plasmids were diluted to $10^{7}, 10^{6}, 10^{5}, 10^{4}, 10^{3}, 10^{2}$ and 10 copies $\mu l^{-1}$. PCR was performed with different plasmid copy numbers and the PCR products were used for hybridization. The primers used for mutagenesis are presented in Table 2.

Production of the chip. The oligonucleotide probe spotting mixture contained $10 \mu \mathrm{l}$ probe dilution $\left(30 \mathrm{pmol} \mu \mathrm{l}^{-1}\right)$ and $10 \mu \mathrm{l}$ spotting solution $(750 \mathrm{mM} \mathrm{NaCl}, 75 \mathrm{mM}$ sodium acetate, $5 \%$ glycerol, $1 \%$ Ficoll and $0.1 \%$ SDS). The spotting mixture was spotted onto silylated glass using a Pixsys 7500 microarrayer (Cartesian). The same oligonucleotide probe was spotted sequentially four times in a row to examine the reproducibility of probe hybridization. The printed slides were left for at least $24 \mathrm{~h}$ at $25{ }^{\circ} \mathrm{C}$, so that the probes could dry onto the slide surface. Probes were spotted onto the glass slides as shown in Fig. 1.

Hybridization and scanning. A $1 \mu \mathrm{l}$ aliquot of digoxigenin-labelled unpurified PCR product was mixed with $10 \mu$ hybridization solution ( $750 \mathrm{mM} \mathrm{NaCl}, 75 \mathrm{mM}$ sodium acetate, $0.2 \%$ SDS, $1 \mathrm{mg}$ fragmented salmon sperm DNA $\mathrm{ml}^{-1}, 2.5 \%$ formamide). The mixture was denatured for $5 \mathrm{~min}$ at $95{ }^{\circ} \mathrm{C}$, chilled on ice for $5 \mathrm{~min}$, and $10 \mu \mathrm{l}$ was applied to the oligonucleotide probe area and covered with a coverslip. Hybridization was performed at $37{ }^{\circ} \mathrm{C}$ for $30 \mathrm{~min}$ in a hybridization chamber. After hybridization, the hybridized slide was

Table 1. Probes for detection of the SNPs in the 23S rRNA gene from $H$. pylori

Bases associated with the wild-type/mutant type to be detected are indicated in bold.

\begin{tabular}{|c|c|c|}
\hline Probe & WT/mutant detected & Probe sequence $\left(5^{\prime} \rightarrow 3^{\prime}\right)$ \\
\hline $\mathrm{P} 1$ & $2142,2143(\mathrm{WT})$ & $\left(\mathrm{NH}_{2}\right) \mathrm{T}_{10}$ AGACGGAAAGACCCC \\
\hline P2 & A2142G & $\left(\mathrm{NH}_{2}\right) \mathrm{T}_{10}$ CAAGACGGGAAGACC \\
\hline P3 & A2142C & $\left(\mathrm{NH}_{2}\right) \mathrm{T}_{10}$ AGACGGCAAGACCCC \\
\hline $\mathrm{P} 4$ & $\mathrm{~A} 2142 \mathrm{G}, \mathrm{A} 2143 \mathrm{G}$ & $\left(\mathrm{NH}_{2}\right) \mathrm{T}_{10}$ CAAGACGGGGAGACC \\
\hline P5 & A2142G, A2143C & $\left(\mathrm{NH}_{2}\right) \mathrm{T}_{10}$ CAAGACGGGCAGACC \\
\hline P6 & A2143G & $\left(\mathrm{NH}_{2}\right) \mathrm{T}_{10}$ AAGACGGAGAGACCCC \\
\hline P7 & A2143C & $\left(\mathrm{NH}_{2}\right) \mathrm{T}_{10} \mathrm{AAGACGGACAGACCCC}$ \\
\hline P8 & A2142C, A2143G & $\left(\mathrm{NH}_{2}\right) \mathrm{T}_{10}$ CAAGACGGCGAGACCC \\
\hline P9 & $2224(\mathrm{WT})$ & $\left(\mathrm{NH}_{2}\right) \mathrm{T}_{10}$ AAGTAAGGGCTTTGGCT \\
\hline P10 & A2142C, A2143C & $\left(\mathrm{NH}_{2}\right) \mathrm{T}_{10}$ CAAGACGGCCAGACCC \\
\hline P11 & G2224A & $\left(\mathrm{NH}_{2}\right) \mathrm{T}_{10}$ AAGTAAAGGCTTTGGCT \\
\hline P12 & PC & $\left(\mathrm{NH}_{2}\right) \mathrm{T}_{10}$ AATGGCGTAACGAGATGG \\
\hline P13 & NC & $\left(\mathrm{NH}_{2}\right) \mathrm{T}_{10}$ AATGGCGTGGCGAGATGG \\
\hline
\end{tabular}

WT, Wild-type. 
Table 2. Primers for site-directed mutagenesis

Point mutations in the $23 \mathrm{~S}$ rRNA gene sequence are indicated in bold.

\begin{tabular}{|c|c|c|c|}
\hline Genotype & Clone & Primer name & Sequence $\left(5^{\prime} \rightarrow 3^{\prime}\right)$ \\
\hline \multirow[t]{2}{*}{ A2142G } & HC23S-1 & GAF & AAGACGGGAAGACCCCGTGGA \\
\hline & & GAR & GGGGTCTTCCCGTCTTGCCG \\
\hline \multirow[t]{2}{*}{ A2142C } & HC23S-2 & CAF & AAGACGGCAAGACCCCGTGGA \\
\hline & & CAR & GGGTCTTGCCGTCTTGCCG \\
\hline \multirow[t]{2}{*}{ A2143G } & HC23S-3 & AGF & AAGACGGAGAGACCCCGTGGA \\
\hline & & AGR & GGGGTCTCTCCGTCTTGCCG \\
\hline \multirow[t]{2}{*}{ A2143C } & $\mathrm{HC} 23 \mathrm{~S}-4$ & $\mathrm{ACF}$ & AAGACGGACAGACCCCGTGGA \\
\hline & & ACR & GGGTCTGTCCGTCTTGCCG \\
\hline \multirow[t]{2}{*}{ G2224A } & HC23S-5 & $\mathrm{AAF}$ & TGAAGTAAAGGCTTTGGCTCT \\
\hline & & AAR & AAAGCCTTTACTTCAAAGC \\
\hline
\end{tabular}

washed sequentially in washing solution A $(150 \mathrm{mM} \mathrm{NaCl}, 15 \mathrm{mM}$ sodium acetate, $0.2 \%$ SDS, $\mathrm{pH} 7.5)$ for $10 \mathrm{~min}(60-100$ r.p.m. on a shaker) followed by solution $\mathrm{B}(150 \mathrm{mM} \mathrm{NaCl}, 150 \mathrm{mM}$ toxilic acid, $0.3 \%$ Tween $20, \mathrm{pH} 7.5$ ) for $1 \mathrm{~min}$. The hybridized slide was dried with absorbent paper, $20 \mu \mathrm{l} 1: 2500$-diluted alkaline phosphataseconjugated anti-digoxigenin (Roche) was added and the slide was incubated at $30{ }^{\circ} \mathrm{C}$ for $30 \mathrm{~min}$. A $50 \mu \mathrm{l}$ aliquot of detection buffer $(0.1 \mathrm{M}$ Tris/HCl $(\mathrm{pH}$ 9.5), $0.1 \mathrm{M} \mathrm{NaCl})$ was added to the hybridization area for $1 \mathrm{~min}$ and then the hybridized slide was washed in washing solution A for $1 \mathrm{~min}$. A piece of nylon membrane $\left(\sim 1 \mathrm{~cm}^{2}\right)$ was soaked in 1:50-diluted substrate (5-bromo-4-chloro-3indolyl phosphate/nitro blue tetrazolium; Roche) solution for $10 \mathrm{~s}$ and placed over the hybridization area away from light at room temperature for $30 \mathrm{~min}$. For the final step, the nylon membrane was washed in $\mathrm{ddH}_{2} \mathrm{O}$ and dried at room temperature. The nylon membrane was scanned with an EPSON Perfection 1640SU scanner or examined with a magnifying lens.

Sequence analysis. To confirm the results of the DNA chip, all PCR products were sequenced. DNA sequencing was performed by Shanghai Bioasia Biotechnology with an ABI Prism 3730 genetic analyzer (Applied Biosystems).

$\begin{array}{cccc}0000 & 0000 & \bullet & 1 \\ 0000 & 0000 & \bullet & 2 \\ 0000 & 0000 & \bullet & 3 \\ 0000 & 0000 & \bullet & 4 \\ 0000 & 0000 & \bullet & 5 \\ 0000 & 0000 & \bullet & 6 \\ \mathrm{~A} & \mathrm{~B} & \mathrm{C} & \end{array}$

Fig. 1. Diagram of the probe layout on the DNA chip. C1-6, PC; A1, A2142G mutation; B1, wild-type nt 2142/2143; A2, A2142G/A2143G mutation; B2, A2142C mutation; A3, A2143G mutation; B3, A2142G/A2143C mutation; A4, A2142C/A2143G mutation; B4, A2143C mutation; A5, A2142C/A2143C mutation; B5, wild-type nt 2224; A6, G2224A mutation; B6, NC. Each probe in columns A and B was spotted sequentially four times in a row to examine the reproducibility of probe hybridization.

\section{RESULTS AND DISCUSSION}

\section{Single-nucleotide polymorphism (SNP) genotyping using a DNA chip}

The mechanism of CAM resistance in $H$. pylori is mostly due to point mutations in the peptidyltransferase-encoding region of the $23 \mathrm{~S}$ rRNA gene. CAM inhibits protein synthesis by binding to the peptidyltransferase loop of $23 \mathrm{~S}$ rRNA. Mutations A2142G/C and A2143G are the most commonly associated with macrolide resistance in natural H. pylori strains (Kato et al., 2002; Kim et al., 2004; Mégraud, 2004; Van Doorn et al., 2001). Recently, a new point mutation, G2224A, was found to be related to CAM resistance in $H$. pylori isolates in north-east China (Hao et al., 2004). Thus, probes were designed and a DNA chip was produced to detect the SNPs at these three sites (nt 2142, 2143 and 2224). In this study, only one mutation of the $23 \mathrm{~S}$ rRNA gene, A2143G, was observed in gastric tissue biopsy specimens and strains. The prevalence of this mutation was $17.46 \%$, higher than that reported by Liu et al. (2008), who found that that primary prevalence of the A2143G mutation was $10-14 \%$ in a Chinese population without a history of CAM therapy (Liu et al., 2008). It may be relevant that we did not distinguish between primary and secondary drug resistance. We did not find the A2142G/C, A2143C or G2224A mutation in any of our samples. The absence of these mutation types in east China may be due to geographical differences. The genotype distributions in our samples are shown in Table 3.

\section{MICs of $H$. pylori strains with the A2143G mutation}

In East Asia, studies from Japan and Korea showed that more than $90 \%$ of CAM-resistant strains of $H$. pylori had the A2143G mutation (Kato et al., 2002; Kim et al., 2002; Maeda et al., 2000). A study from China (Pan et al., 2002) showed the A2143G mutation present in $100 \%$ of CAMresistant $H$. pylori. We also determined MIC values by Etest. A total of $10 \mathrm{H}$. pylori strains were isolated successfully from 11 gastric biopsy specimens (H. pylori 
Table 3. SNP results of the $H$. pylori 23S rRNA gene from 63 gastric tissue biopsy specimens using the DNA chip

\begin{tabular}{|lcccc|}
\hline \multirow{2}{*}{ Nucleotide } & \multicolumn{4}{c|}{ Genotype } \\
\cline { 2 - 5 } & A & G & C & T \\
\hline 2142 & $63 / 63(100 \%)$ & 0 & 0 & 0 \\
2143 & $52 / 63(82.54 \%)$ & $11 / 63(17.46 \%)$ & 0 & 0 \\
2224 & 0 & $63 / 63(100 \%)$ & 0 & 0 \\
\hline
\end{tabular}

could not be isolated from T23) with the A2143G mutation. The CAM MIC values of these ten H. pylori strains ranged from 4 to $256 \mu \mathrm{g} \mathrm{ml}^{-1}$. All of the A2143G mutations in the CAM-resistant strains were confirmed in our study by sequencing.

\section{Comparison of the DNA chip and DNA sequencing}

To evaluate the specificity of the probes, we compared the results of our DNA chip with DNA sequencing using plasmids constructed by site-directed mutagenesis. Amplification products of clones HC23S-1, HC23S-2, HC23S-3, HC23S-4 and HC23S-5 (Table 2) were hybridized to the probes and the results were consistent with the respective probe locations (data not shown). The results of the DNA chip and DNA sequencing were almost identical. Out of 63 gastric tissue samples (T1-T63), the results of the DNA chip were concordant with DNA sequencing in $96.83 \%(61 / 63)$. DNA sequencing of two samples, T8 and T40, was unsuccessful, probably because the DNA concentration of these samples was lower than the other samples, although the DNA chip was able to detect whether these two gastric tissue samples had a mutation. One reason for this discrepancy is that the microarray-based method may be less affected than direct sequencing by the fragmentation of DNA caused by processing of the tissue. Another reason is that it is possible that the microarraybased method can detect smaller amounts of mutant, whilst direct DNA sequencing requires higher levels (Taylor et al., 1997). We also compared the information about the point mutations in the $23 \mathrm{~S}$ rRNA gene of the ten CAM-resistant $H$. pylori strains with the corresponding biopsy specimens using the DNA chip. The results showed a complete concordance between the biopsy specimens and the H. pylori strains. The results of DNA chip and DNA sequencing are shown in Fig. 2.

\section{Sensitivity and reproducibility of the DNA chip}

To evaluate the sensitivity of hybridization with the DNA chip, recombinant plasmids were diluted to $10^{7}, 10^{6}, 10^{5}$, $10^{4}, 10^{3}, 10^{2}$ and 10 copies $\mu 1^{-1}$. The sensitivity of this assay was $1.53 \times 10^{2}$ copies of $H$. pylori DNA $\mu l^{-1}$ (data not shown). Thus, based on this result, the microarray-based method would not be a suitable approach if the amount of template is less than 100 copies of the $23 \mathrm{~S}$ rRNA gene. We randomly selected five clinical samples and tested each sample five times using our colorimetric enzyme assay. The results of this assay were concordant, indicating that the assay had good reproducibility (data not shown).

\section{Evaluation of the quality of the DNA chip and optimization of probes}

To evaluate the quality of chip production and hybridization, the PC probe used in this study was designed to be (a)

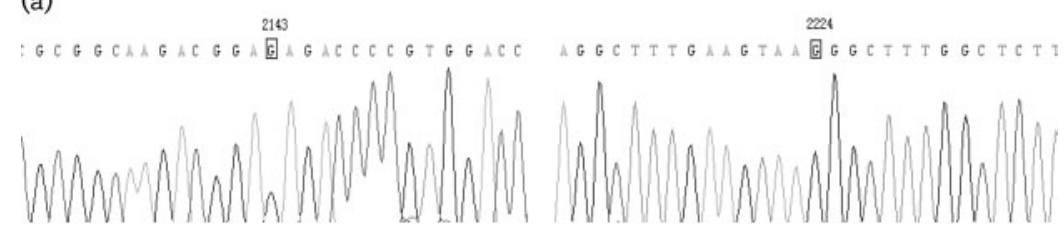

(b)

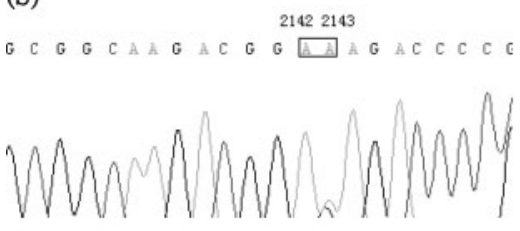

(c)

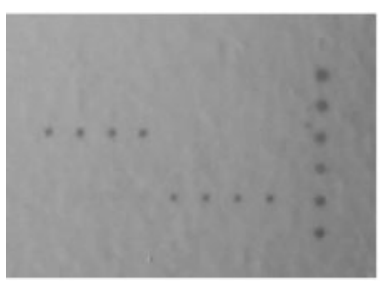

(d)

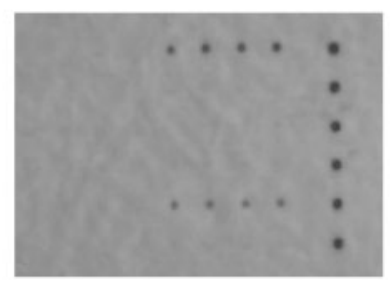

Fig. 2. Comparison of results from sequencing analysis and the DNA chip. (a, c) Sequence analysis (a) of the A2143G mutant and wild-type nt 2224, which yielded the same results as the DNA chip (c). (b, d) Sequencing analysis (b) of the wild-type nt 2142, 2143 and 2224 , which yielded the same results as the DNA chip (d). 
complementary to HPRP. We designed the NC probe by substituting two base mismatches compared with the sequence of HPRP. The NC probe was thus used to evaluate whether non-specific hybridization occurred. In order to increase the hybridization efficiency of the assay, the lengths of the probes and spacer arms and the hybridization conditions were optimized. A probe length of 15-18 nt with a poly $(\mathrm{T})_{10}$ spacer was found to be optimal.

The prevalence of $H$. pylori infection, which is higher in developing countries and low socio-economic populations (Bener et al., 2002; Strnad et al., 2002), is about one-half of the world's population (Dunn et al., 1997). It is widely accepted that all patients with gastric or duodenal ulcers and $H$. pylori infection should be treated with antimicrobial agents, as eradication of the bacteria cures peptic ulcer disease and efficiently prevents relapse (Drumm et al., 2000). However, patients in unsuccessful eradication groups have been found to be infected with strains of $H$. pylori that become more resistant to CAM on exposure to the drug (Kobayashi et al., 2006). The prevalence of CAM resistance is increasing, which may be due to the more extensive use of macrolides (Buzás et al., 2007). In China, the resistance rates of $H$. pylori to CAM in Beijing were $10.0 \%$ in $1999-2000$ and $18.3 \%$ in 2001-2002 (Cheng \& $\mathrm{Hu}, 2005)$. Thus, prediction of CAM resistance plays a key role before treatment in the eradication of $H$. pylori. Antibiotic susceptibility tests have been considered the 'gold standard' for confirmation of the resistance of $H$. pylori. However, isolation of $H$. pylori from gastric biopsies is affected by the biopsy preparation, culture conditions and the medium used. It has been reported that isolation rates of $H$. pylori from infected individuals vary from 23.5 to $97 \%$ (Fresnadillo Martínez et al., 1997; Heep et al., 1999). In the present study, the isolation rate of $H$. pylori from 63 gastric biopsy specimens was $79.37 \%(50 / 63)$. $H$. pylori was not isolated successfully from 13 gastric biopsy specimens, although the DNA extracted from the corresponding biopsy specimen could be used for detecting the mutant using the DNA chip. To detect mutants associated with antibiotic resistance and identify the mutation types, many molecular methods have been used. However, these methods can generally detect only one specific marker per reaction (Chizhikov et al., 2002). Compared with these methods, an oligonucleotide chip-based method is less time-consuming and is highly sensitive for the detection of point mutations (Xing et al., 2005).

In conclusion, our method detected point mutations in the $23 \mathrm{~S}$ rRNA gene of $H$. pylori accurately and rapidly $(<5 \mathrm{~h})$, and we could process many samples simultaneously. Thereby, our colorimetric DNA chip for detecting the resistance gene in $H$. pylori is highly specific, has a high throughput and is also technically feasible for clinical application. Compared with a fluorescence microarray, the colorimetry chip has a similar sensitivity and the results are easy to interpret (Mao et al., 2006). In addition, the laser scanner and Cy3/Cy5-labelled dUTPs required for fluor- escence microarray are expensive, limiting this method for general clinical application. A colorimetric DNA chip does not require expensive instruments such as a laser scanner. Therefore, because of its lower cost and simplicity, a colorimetric DNA chip is technically feasible for clinical application, especially for small- and medium-sized hospitals in developing countries.

\section{ACKNOWLEDGEMENTS}

This work was supported by grants from the Key Subject of Jiangsu Province (xk2007320).

\section{REFERENCES}

Bener, A., Uduman, S. A., Ameen, A., Alwash, R., Pasha, M. A., Usmani, M. A., Al-Naili, S. R. \& Amiri, K. M. (2002). Prevalence of Helicobacter pylori infection among low socio-economic workers. $J$ Commun Dis 34, 179-184.

Buzás, G. M., Lotz, G. \& Kiss, A. (2007). The epidemiology of clarithromycin resistance of Helicobacter pylori infection in Hungary. Orv Hetil 148, 1461-1467.

Cheng, H. \& Hu, F. L. (2005). The epidemiology of Helicobacter pylori resistance to antibiotics in Beijing. Zhonghua Yi Xue Za Zhi 85, 27542757 (in Chinese).

Chizhikov, V., Wagner, M., Ivshina, A., Hoshino, Y., Kapikian, A. Z. \& Chumakov, K. (2002). Detection and genotyping of human group A rotaviruses by oligonucleotide microarray hybridization. J Clin Microbiol 40, 2398-2407.

Drumm, B., Koletzko, S. \& Oderda, G. (2000). Helicobacter pylori infection in children: a consensus statement. European Paediatric Task Force on Helicobacter pylori. J Pediatr Gastroenterol Nutr 30, 207-213.

Dunn, B. E., Cohen, H. \& Blaser, M. J. (1997). Helicobacter pylori. Clin Microbiol Rev 10, 720-741.

Fresnadillo Martínez, M. J., Rodríguez Rincón, M., Blázquez de Castro, A. M., García Sánchez, E., García Sánchez, J. E., Trujillano Martín, I., Cordero Sánchez, M., Alvarez Alvarez, P., Paz Bouza, J. \& García-Rodríguez, J. A. (1997). Comparative evaluation of selective and nonselective media for primary isolation of Helicobacter pylori from gastric biopsies. Helicobacter 2, 36-39.

Hao, Q., Li, Y., Zhang, Z. J., Liu, Y. \& Gao, H. (2004). New mutation points in 23S rRNA gene associated with Helicobacter pylori resistance to clarithromycin in northeast China. World J Gastroenterol 10, 1075-1077.

Heep, M., Scheibl, K., Degrell, A. \& Lehn, N. (1999). Transport and storage of fresh and frozen gastric biopsy specimens for optimal recovery of Helicobacter pylori. J Clin Microbiol 37, 3764-3766.

Kato, S., Fujimura, S., Udagawa, H., Shimizu, T., Maisawa, S., Ozawa, K. \& linuma, K. (2002). Antibiotic resistance of Helicobacter pylori strains in Japanese children. J Clin Microbiol 40, 649-653.

Kim, K. S., Kang, J. O., Eun, C. S., Han, D. S. \& Choi, T. Y. (2002). Mutations in the 23S rRNA gene of Helicobacter pylori associated with clarithromycin resistance. J Korean Med Sci 17, 599-603.

Kim, J. M., Kim, J. S., Jung, H. C., Kim, N., Kim, Y. J. \& Song, I. S. (2004). Distribution of antibiotic MICs for Helicobacter pylori strains over a 16-year period in patients from Seoul, South Korea. Antimicrob Agents Chemother 48, 4843-4847.

Kobayashi, I., Saika, T., Muraoka, H., Murakami, K. \& Fujioka, T. (2006). Helicobacter pylori isolated from patients who later failed 
H. pylori eradication triple therapy readily develop resistance to clarithromycin. J Med Microbiol 55, 737-740.

Liu, Z., Shen, J., Zhang, L., Shen, L., Li, Q., Zhang, B., Zhou, J., Gu, L., Feng, G. \& other authors (2008). Prevalence of A2143G mutation of H. pylori-23S rRNA in Chinese subjects with and without clarithromycin use history. BMC Microbiol 8, 81.

Maeda, S., Yoshida, H., Matsunaga, H., Ogura, K., Kawamata, O., Shiratori, Y. \& Omata, M. (2000). Detection of clarithromycinresistant Helicobacter pylori strains by a preferential homoduplex formation assay. J Clin Microbiol 38, 210-214.

Mao, H., Wang, H., Zhang, D., Mao, H., Zhao, J., Shi, J. \& Cui, Z. (2006). Study of hepatitis B virus gene mutations with enzymatic colorimetry-based DNA microarray. Clin Biochem 39, 67-73.

Mégraud, F. (2004). H. pylori antibiotic resistance: prevalence, importance, and advances in testing. Gut 53, 1374-1384.

Pan, Z. J., Su, W. W., Tytgat, G. N., Dankert, J. \& Van der Ende, A. (2002). Assessment of clarithromycin-resistant Helicobacter pylori among patients in Shanghai and Guangzhou, China, by primermismatch PCR. J Clin Microbiol 40, 259-261.

Rüssmann, H., Adler, K., Haas, R., Gebert, B., Koletzko, S. \& Heesemann, J. (2001). Rapid and accurate determination of genotypic clarithromycin resistance in cultured Helicobacter pylori by fluorescent in situ hybridization. J Clin Microbiol 39, 4142-4144.

Sezgin, O., Aslan, G., Altintaş, E., Tezcan, S., Serin, M. S. \& Emekdaş, G. (2008). Detection of point mutations on 23S rRNA of Helicobacter pylori and resistance to clarithromycin with PCR-RFLP in gastric biopsy specimens in Mersin, Turkey. Turk J Gastroenterol 19, 163-167.

Strnad, M., Presecki, V., Babus, V., Turek, S., Dominis, M., Kalenić, S., Hebrang, A. \& Katicić, M. (2002). Epidemiology of Helicobacter pylori infection. Lijec Vjesn 124 (Suppl. 1), 5-9.

Sung, J. J., Chung, S. C., Ling, T. K., Yung, M. Y., Leung, V. K., Ng, E. K., Li, M. K., Cheng, A. \& Li, A. K. (1995). Antibacterial treatment of gastric ulcers associated with Helicobacter pylori. N Engl J Med 332, 139-142.

Taylor, D. E., Ge, Z., Purych, D., Lo, T. \& Hiratsuka, K. (1997). Cloning and sequence analysis of two copies of a $23 \mathrm{~S}$ rRNA gene from Helicobacter pylori and association of clarithromycin resistance with $23 S$ rRNA mutations. Antimicrob Agents Chemother 41, 2621-2628.

Treiber, G., Kist, M., Klotz, U., Peitz, U. \& Malfertheiner, P. (2005). Therapie der Helicobacter-pylori-infektion: klinische, mikrobiologische und pharmakologische aspekte. Dtsch Arztebl 26, 1883-1888 (in German).

Van Doorn, L. J., Glupczynski, Y., Kusters, J. G., Me'graud, F., Midolo, P., Maggi-Solca, N., Queiroz, D. M. M., Nouhan, N., Stet, E. \& Quint, W. G. V. (2001). Accurate prediction of macrolide resistance in Helicobacter pylori by a PCR line probe assay for detection of mutations in the $23 \mathrm{~S}$ rRNA gene: multicenter validation study. Antimicrob Agents Chemother 45, 1500-1504.

Xing, J. Z., Clarke, C., Zhu, L. \& Gabos, S. (2005). Development of a microelectronic chip array for high-throughput genotyping of Helicobacter species and screening for antimicrobial resistance. J Biomol Screen 10, 235-245. 